\title{
Connectivity in the Technology Transfer Process among Local ASEAN Firms
}

\author{
Masatsugu Tsuji ${ }^{1}$, Hiroki Idota ${ }^{2}$, Yasushi Ueki ${ }^{3}$, Hidenori Shigeno ${ }^{1}$, Teruyuki Bunno ${ }^{2}$
}

ABSTRACT

\begin{abstract}
This study focuses on the role of human factors in the innovation processes of firms in four member states of the Association of Southeast Asian Nations (ASEAN), i.e., Indonesia, Thailand, the Philippines, and Vietnam. Firms are required first to obtain new information related to innovation and then to integrate it with their indigenous resources. The innovation process thus consists of the absorptive process, through which outside information is employed to enhance innovation capability, and the transforming process, through which innovation capability creates innovation. This study identifies essential factors that promote these capabilities. In the absorptive process, two types of personnel are examined, i.e., employees who have experience working with multinational companies (MNCs) and those indigenous to the firm. As for the transforming capability, organizational learning processes, including quality control (QC) and cross-functional teams, are examined. Mail surveys were conducted from 2013 to 2014, and the total number of samples was 665. Based on the data, structural equation modeling (SEM) is employed. The analysis demonstrates that MNCs have the largest impact as external linkages. The most important mediators for locals to connect with MNCs are top management and factory managers who have experience working with MNCs, whereas indigenous employees, such as local engineers, managers, and line leaders, are identified for connectivity with locals. The direct and indirect effects of external linkages on innovation are also estimated. In the transforming process, cross-functional teams have a larger impact on innovation than QC.
\end{abstract}

KEY WORDS: absorptive capability, transforming process, organizational learning, cross-functional team, indigeneity

JEL Classification: O32, O31, O19

'Kobe International University, Japan; ${ }^{2}$ Kindai University, Japan;

${ }^{3}$ Economic Research Institute for ASEAN and East Asia, Indonesia

\section{Introduction}

This study aims to analyze the role of human factors in the innovation process in local and global firms located in four ASEAN economies, i.e., Indonesia, Thailand, the

\section{-}

Correspondence concerning this article should be addressed to: Masatsugu Tsuji 9-1-6 Koyocho-naka, Higashinada-ku, Kobe, Hyogo 658-0032, Japan Tel/Fax: +81-78-845-3418, E-mail: mtsuji@kobe-kiu.ac.jp
Philippines, and Vietnam. New information related to technology and consumer needs, which is necessary for innovation, mainly comes from outside a firm (Chesbrough, 2003); therefore, it is required first to obtain such information and then to integrate it with indigenous resources for innovation that are owned by the firm. The resources for innovation that firms own are referred to as firms' internal innovation capability, or innovation capability for short. This is defined as the inte- 
grated ability of a firm to create innovation and consists of the firm's total resources, core competence, or competitiveness. In more detail, internal capability includes the technological level, such as the number of patents, production and research and development (R\&D) facilities; human resources, such as the number of engineers with higher degrees or skills; the level of craftsmanship; work ethics; and the organizational nature of the firm, such as communication between workers and top management, the speed of decision-making, and the leadership of top management. Innovation capability is also divided into two categories, i.e., absorptive and transforming capabilities. The concept of absorptive capability was developed by Cohen and Levinthal (1990), who defined it as a firm's ability to reorganize the value of new external information, assimilate it, and apply it to commercial ends. Zahra and George (2002) broke down absorptive capacity into acquisition, assimilation, transformation, and exploitation. The latter two capabilities, constituting the transforming capability in this study, are used by firms to innovate based on these integrated resources. This study attempts to identify essential factors that promote these capabilities based on the authors' survey data.

In developing countries, MNCs have superiority in technology, know-how, and management, and local firms are required to absorb those capabilities from them. In so doing, local firms must initiate connectivity with MNCs for locals to obtain the necessary information. In earlier studies on the innovation process in the 1960s and 1970s (Allen, 1977; Allen \& Cohen, 1969), personnel who fulfilled functions such as connecting with outside entities and introducing new information were termed "gatekeepers," key factors in the absorptive process. Gatekeepers have sufficient professional skills and knowledge to avoid misunderstandings and can connect organizations by dissolving the barriers between them. On the other hand, after new information is introduced, it has to be diffused and shared among suitable employees engaged in sections related to $\mathrm{R} \& \mathrm{D}$ or innovation. In this diffusion or transformation process-particularly to whom and how new information is diffused-is based on who talks to whom or who organizes research meetings, and it can be analyzed by examining the number of conversations. Personnel who conduct these activities are referred to as "transformers" or "mediators" (Freeman, 1979). Moreover, these personnel initiate and introduce the seeds of innovation, but innovation activities by related sections or whole firms are required to elevate the seeds to innovation. This study refers to these activities as organizational learning, which consists of cross-functional teams and QC, and it examines how the learning process is effective in enhancing innovation.

These are the motivations of the study. Using the survey data and rigorous statistical methods, the key personnel are identified, and the learning process is demonstrated to contribute to innovation.

\section{Literature review}

It is widely accepted that the globalization of economies initiated by MNCs contributes to economic development and innovation in developing economies, as reflected by accumulated research results (Ernst, 2002; Pietrobelli \& Rabellotti, 2011). The survey here is thus restricted to previous papers directly related to the connectivity addressed in this paper, i.e., how local firms connect to other external linkages-consisting of MNCs, universities, and other locals-to promote innovation, how connectivity enhances the innovation capability of locals, and how this capability finally promotes innovation.

The early literature on connectivity between providers and recipients of information via communication was related mainly to conceptual frameworks, including the semantic issues of the terms and taxonomy of connectivity (Allen \& Cohen, 1969; Allen, 1977; Cohen \& Levinthal, 1990; Granovetter, 1973; Leven \& Cross, 2004). The characteristics that determine connectivity are summarized as follows: (i) types of information, such as tacit and explicit knowledge or information redundancy; (ii) trustworthiness between partners, which depends on a common basis such as culture, values, and profession; (iii) intimacy, based on the frequency and density of communications; (iv) strength of ties; and (v) social networks or embeddedness. The last (v) implies that information that is not exchanged in the market is transferred by informal connections/methods (Mkandawire, 2007; Uzzi, 1997). The combination of these characteristics determines the nature of connectivity. Lam (2003), for example, used tacit-explicit and individual-collective characteristics and identified four types of knowledge: 
embrained (individual-explicit), embodied (individual-tacit), encoded (collective-explicit) and embedded (collective-tacit).

In the context of innovation in developing economies, Kesidoua and Szirmai (2008) used an analytical framework similar to this paper to analyze the connectivity among MNCs and locals, taking the Uruguay software industry as an example. Kesidoua and Szirmai did not categorize international or local firms but focused on information flow inside the cluster. Their paper discussed types of knowledge spillovers and channels that result in knowledge transfer via labor mobility and informal connections not involving transactions. Whereas local knowledge spillovers through transactions did not promote innovation, it did contribute to firms' performance in areas such as export. This study has a similar framework to the Kesidoua and Szirmai paper, including the survey method and spillover processes, and similarities and differences will be discussed in the following.

Regarding gatekeepers or moderators from MNCs to locals, Hébert, Very and Beamish (2005) identified expatriate managers dispatched from MNCs, and Tsuji, Ueki and Idota (2014) and Machikita and Ueki (2015) identified guest engineers dispatched by MNCs to locals or sent from local firms to MNCs to obtain new technology, which led to the enhancement of innovation capability.

\section{Hypotheses to be tested}

In developing economies, the agents that own information necessary for innovation are referred to as "external linkages." These are identified by the three categories of MNCs, local firms, and public research organizations and universities. There is a body of literature concerning knowledge transfer from these external linkages to locals, such as Caloghirou, Kastelli and Tsakanikas (2004), Liao, Fei and Chen (2007), and Srholec (2011). Based on these studies, the first hypothesis is postulated:

Hypothesis I: External linkages promote internal innovation capability and accordingly enhance innovation.

The issue of knowledge spillover is another topic with accumulated research results, such as Görg and Strobl (2005), Balsvik (2011), and Poole (2013). This paper, however, attempts to identify concrete personnel who take the initiative to introduce new information from MNCs, such as the gatekeepers of early studies in the 1970s. Based on discussions in the previous section, this study proposes two different categories of connectivity depending on the level of intimacy, proximity, ability, or expertise.

Hypothesis II: Top management or factory managers who have work experience with MNCs are key factors in constructing the connectivity with MNCs.

This hypothesis includes factory managers as gatekeepers because they are more concerned with technology than top management. The hypothesis is thus related to the global trend of regions because MNCs have invested heavily in regions indicating technology transfers through the human factor. On the other hand, locality and proximity among human factors can also be considered, as discussed by Colquitt and Rodell (2011), that is, local employees of both firms can easily develop intimacy. This proximity of human factors leads to the second hypothesis category:

Hypothesis III: Indigenous employees assist in the construction of connectivity with other local firms.

Upon observing the process after information is introduced in the above process, new information has to be diffused and shared among suitable employees engaged in R\&D sections. Research on the diffusion process is another area that has accumulated research. This paper examines particularly to whom and how new information is diffused based on who talks to whom or who organizes research meetings and by examining, among other things, the number of conversations. Personnel who conduct these activities are referred to as "transformers" or "mediators" (Freeman, 1979). Gatekeepers and transformers can be the same persons. In addition to knowledge transfer, this paper examines the role of these personnel on organizational learning, such as cross-functional teams and QC-that is, they introduce or deepen these learning processes. Thus, the following hypotheses are proposed:

Hypothesis IV: Working experience with MNCs promotes organizational learning. 


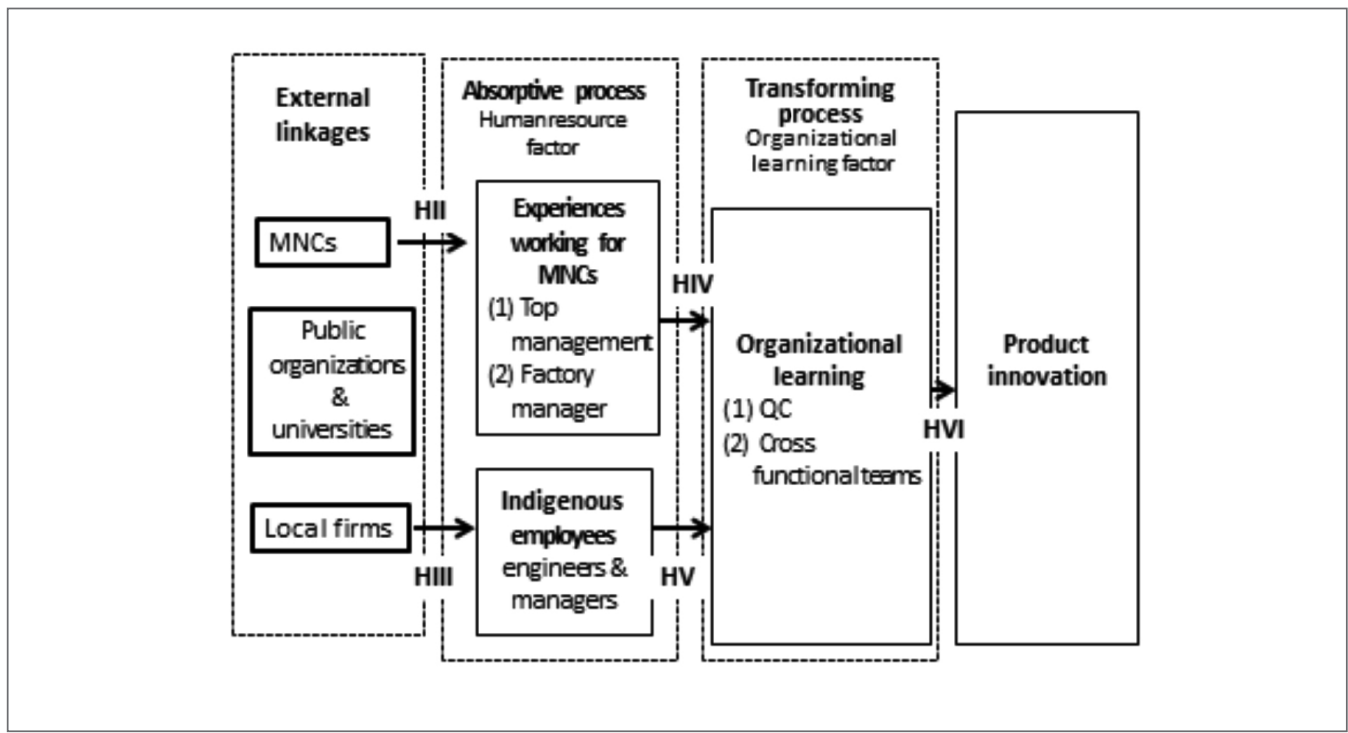

Figure 1. Structure of the Model

Note: $\mathrm{HI}$ is not indicated here.

Hypothesis V: Indigenous employees promote organizational learning.

The following hypothesis shows the relationship between organizational learning and innovation. Organizational learning serves an important function in the innovation process and thus forms the final hypothesis.

Hypothesis VI: Organizational learning enhances innovation.

\section{Data and methodology}

\section{Surveys and method}

This study is based on mail surveys and phone interviews conducted with respect to firms in four ASEAN countries, i.e., Indonesia, Thailand, the Philippines, and Vietnam. The first three countries have a longer tradition of introducing MNCs, while the last has a shorter tradition, which balances old and new. The sample includes 1,232 companies in the Hanoi area and 1,000 in the Ho Chi Minh City area in Vietnam; 239 in Batangas and other areas in the Philippines; 437 in the Jabodetbek area in Indonesia; and 878 in Greater Bangkok,
Thailand. The surveys were conducted from 2014 to 2015. The numbers of valid responses were 149 from the Hanoi area (12.09\%), 171 from Ho Chi Minh City (17.10\%), 157 from Indonesia (35.93\%), 237 from the Philippines (99.16\%), and 284 from Thailand (32.35\%).

This study employs structural equation modeling (SEM) or covariance structural analysis (CSA), which made it possible to study the relationships among a number of variables that are related to each other. SEM is said to be a mixture of factor analysis and regression analysis. Thus, SEM analysis can be used even for cases in which the variables are endogenous and the usual least squares method cannot be applied (Bagozzi, 1980; Bock, 1960; Bock \& Bargmann, 1966; Bollenn, 1989)

\section{Model}

To analyze the above research question, a model is constructed to examine the following relationships between latent variables, which are related to the hypotheses stated earlier:

1. External linkages such as MNCs and public research organizations promote the working experience of top management and factory managers 


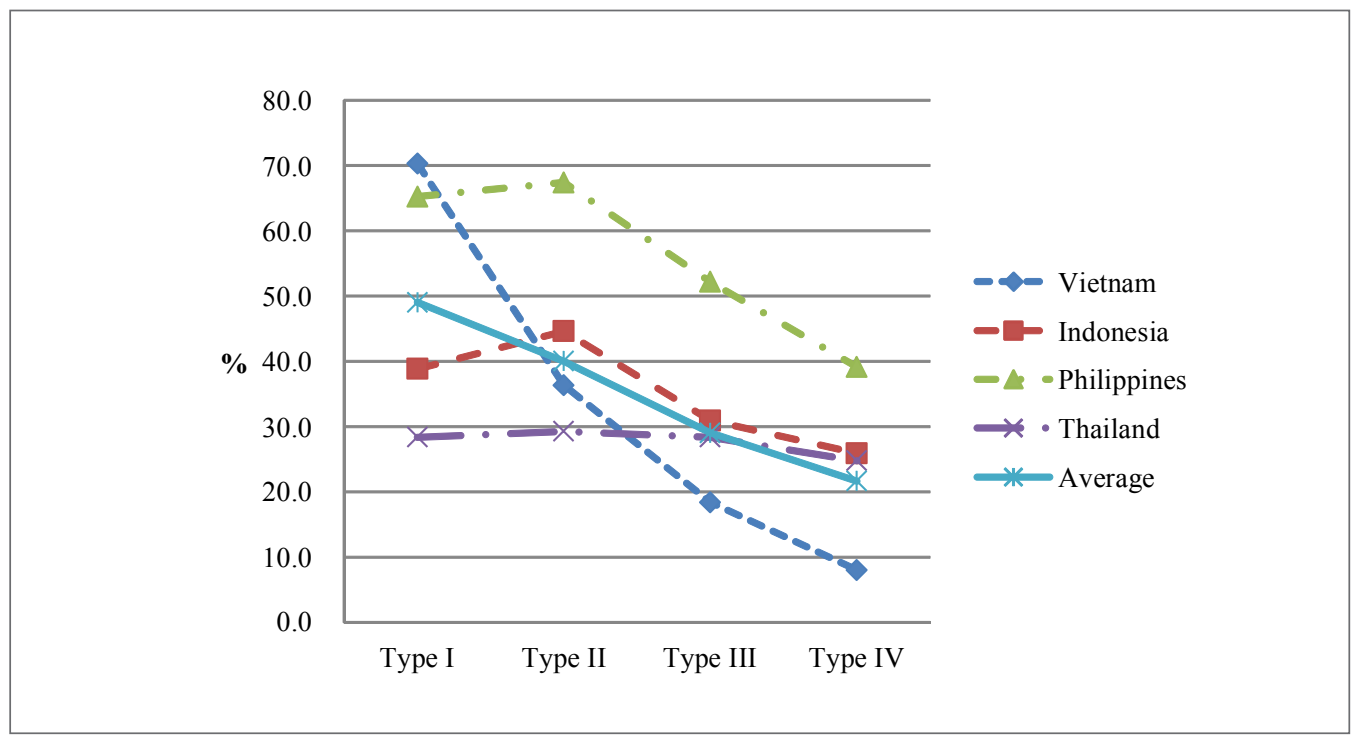

Figure 2. Distribution of Innovation by Country

with MNCs, which supports the connectivity with MNCs (Hypotheses I and II).

2. External linkages such as locals support connectivity with local firms by indigenous employees (Hypothesis III).

3. Working experience with MNCs and indigenous employees both promote organizational learning (Hypotheses IV and V).

4. Organizational learning enhances product innovation (Hypothesis VI).

The above relationships are summarized in Figure 1.

\section{Construction of variables: Outcome variables}

The construction of variables related to product innovation is based on the following four categories of innovation (see Q13 in Table 1):

(1) Innovation Type I: Introduction of a new product, redesigning packaging or significantly changing the appearance design of your existing products

(2) Innovation Type II: Introduction of a new product, significantly improving your existing products with respect to their capabilities, user friendliness, components, subsystems, etc.
(3) Innovation Type III: Development of a totally new product based on the "existing" technologies at your establishment

(4) Innovation Type IV: Development of a totally new product based on "new" technologies at your establishment

For each category, the respondents were asked whether they had achieved, attempted, or not attempted the innovation. If respondents had achieved the innovation, two points are given; if they had attempted the innovation, one point is given; and those who had not yet attempted the innovation are indicated by zero. With respect to the above four questions, promax rotation by factor analysis is employed. Consequently, the variables converge to one factor, called "product innovation." The innovation situation in each individual country is summarized in Figure 2, which shows that the quality of innovation increases from Type I to Type IV, and the distribution of Vietnam is typical. However, in the case of Indonesia and the Philippines, a peak is observed at Type II, and in the case of Thailand, a peak is located at Type III. The average of the four countries is indicated by "Average." 
Table 1. Basic Statistics

N Min Max Ave. S.D.

Outcome variables

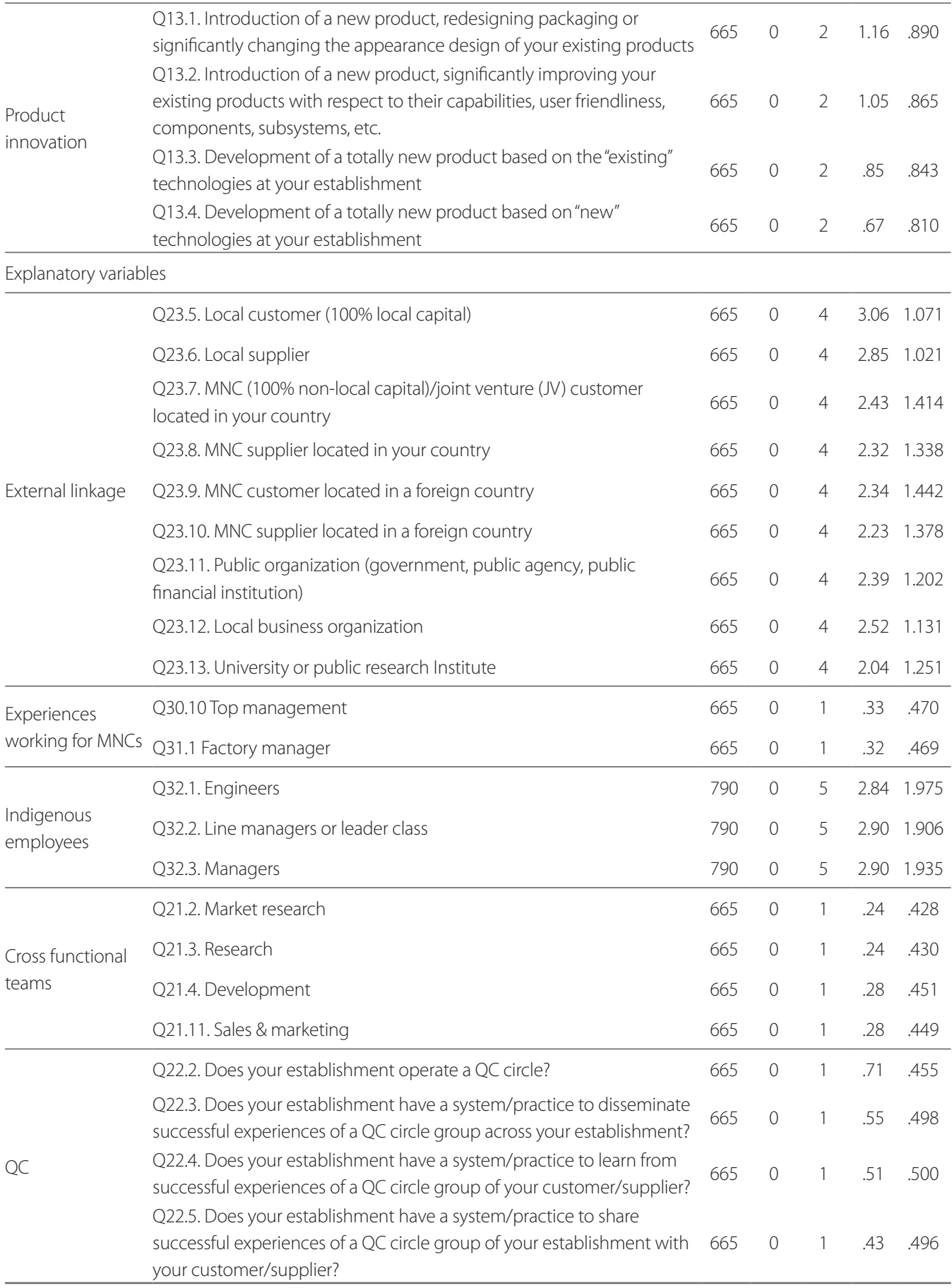


Table 2. Results of Structural Equation Modeling

\begin{tabular}{llcccc}
\hline From & To & $\begin{array}{c}\text { Standardizing } \\
\text { Coefficient }\end{array}$ & SE & t value & p value \\
\hline Local firms & Experiences of working for MNCs & -0.249 & 0.025 & $-3.158^{* * *}$ & 0.002 \\
MNCs & Experiences of working for MNCs & 0.499 & 0.019 & $6.019^{* * *}$ & 0.000 \\
Public organizations \& universities & Experiences of working for MNCs & 0.138 & 0.021 & $1.674^{*}$ & 0.094 \\
\hline Local firms & Indigenous employees & 0.216 & 0.116 & $4.155^{* * *}$ & 0.000 \\
MNCs & Indigenous employees & -0.217 & 0.076 & $-4.691^{* * *}$ & 000 \\
Experiences working for MNCs & Organizational learning & 0.492 & 0.298 & $4.659^{* * *}$ & 000 \\
Indigenous employees & Organizational learning & 0.201 & 0.025 & $3.206^{* * *}$ & 0.001 \\
\hline Organizational learning & QC & 0.423 & - & - & - \\
Organizational learning & Cross-functional teams & 0.439 & 0.144 & $5.386^{* * *}$ & 0.000 \\
\hline Organizational learning & Product innovation & 0.587 & 0.086 & $5.25^{* * *}$ & 0.000 \\
\hline
\end{tabular}

Notes: ${ }^{* *},{ }^{* *}$ and ${ }^{*}$ indicate levels of significance of $1 \%, 5 \%$, and $10 \%$, respectively.

The effects in the latent variables are indicated only for organizational learning, and the p-value of "from organizational learning to QC" cannot be calculated because these pass coefficients are fixed to 1.

\section{Explanatory variables}

\section{(1) External linkages}

The questions related to the explanatory variables are summarized in Table 1. First, the latent variables of external linkages are constructed in the following manner. The respondents were asked to rate linkages according to a five-point scale: 4 . Very important, 3. Somewhat important, 2. Not very important, 1. Not important, and 0 . Not practiced. The scores are assigned values from 0 to 4 points. Three factors, that is, "local firms," "MNCs," and "public organization and university," are extracted by factor analysis.

\section{(2) Internal innovation capability}

\section{(2-1) Organizational learning}

The variable for organizational learning consists of two questions: quality control (QC) and crossfunctional team. The questions regarding QC are summarized in Table 1. If respondents replied "Yes," then the score is 1 ; otherwise, it is 0 . Accordingly, this variable takes values from 0 to 5 .

\section{(2-2) Cross-functional team}

This variable is constructed from Q21, and the questions are limited to the areas related to product innovation, i.e., 2. Market Research, 3. Research, 4. Development, 11. Sales and Marketing. If respondents replied "Yes," then the score is 1 ; otherwise, it is 0 . Accordingly, this variable takes values from 0 to 5 .

\section{(3) Gatekeepers}

\section{(3-1) Working experience with MNCs}

The related questions ask about the backgrounds of top management and factory managers, as shown in Table 1. If respondents reply "Yes," then a score of 1 is given; otherwise, the score is 0 .

\section{(3-2) Indigenous employees}

This variable is based on Q32: "What percent of engineers/line managers/managers are indigenous?" The respondents were asked to choose one among five categories: (0) $0-19 \%-1$, (1) $20-39 \%$, (2) 40 $59 \%$, (3) $60-79 \%$, (4), $80-99 \%$, or (5) $100 \%$. The scores for these questions coincide with the number of the response, that is, $100 \%$ is given 5 and so on. This variable takes values from 0 to 5 .

Summarizing the above discussions, the basic statistics for the above variables are shown in Table 1 .

\section{Estimation results}

\section{Results}

The results of the SEM are summarized in Table 2, and the path diagram based on the results is shown 


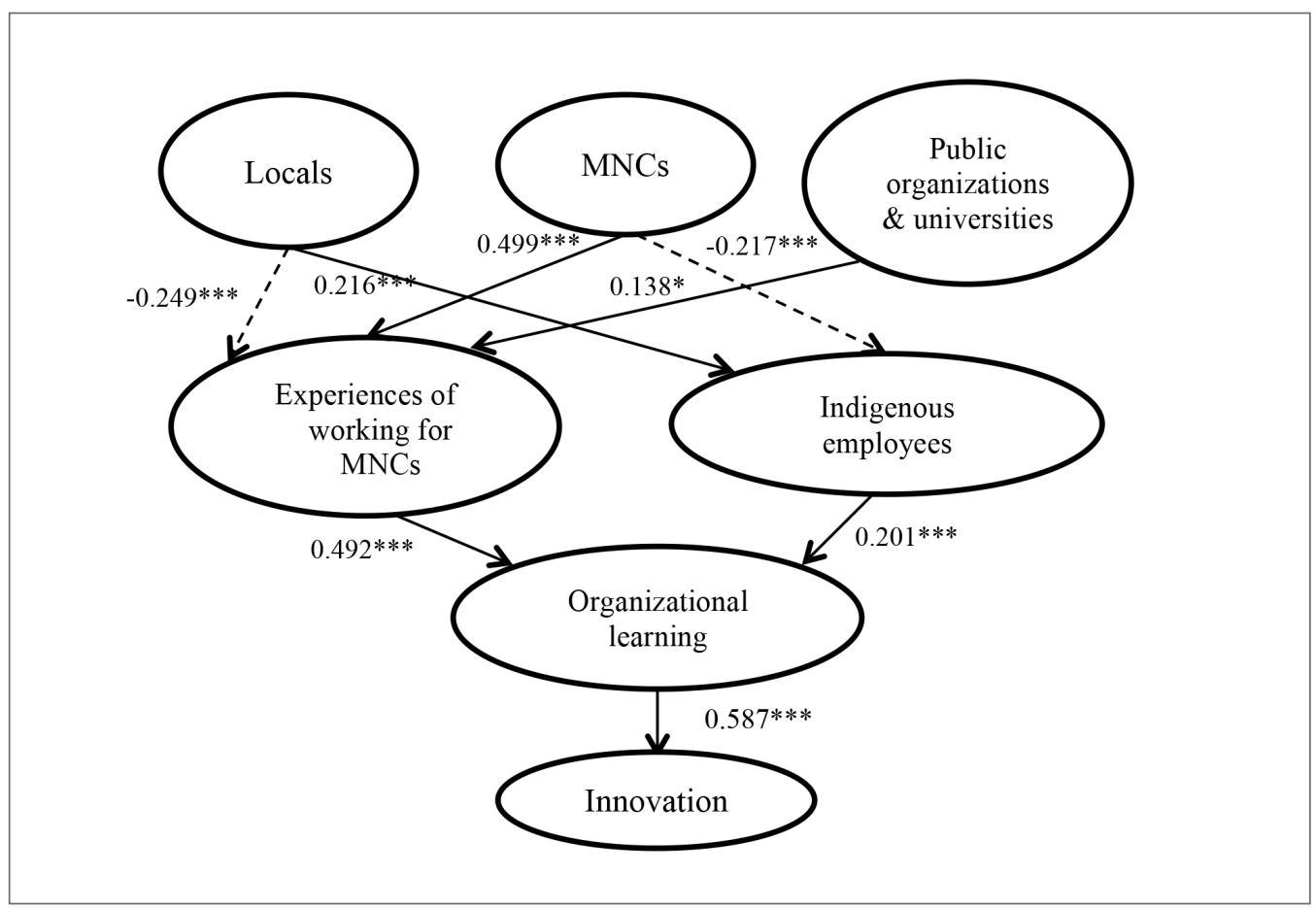

Figure 3. Path Diagram of Estimation

Note: ${ }^{* *},{ }^{* *}$ and ${ }^{*}$ indicate levels of significance of $1 \%, 5 \%$, and $10 \%$, respectively.

in Figure 3. Working experience with MNCs is a significant factor for connecting to MNCs and public organizations and universities, whereas indigenous employees are mediators for connecting with locals. The relationships between locals and working experience with MNCs and between MNCs and indigenous employees are not significant. Other latent variables, such as working experience with MNCs, indigenous employees, and organizational learning, are positive and significant for innovation.

\section{Fitness of the model}

The fitness of the SEM model is determined by the goodness-of-fit index (GFI) and the adjusted goodnessof-fit index (AGFI), which take a value between 0 and 1 , indicating the criteria for the explanatory power of the model. If GFI $\geq$ AGFI and both indices are 0.9 or more, the model can be judged as proper. The comparative fit index (CFI) evaluates the model in terms of goodness- of-fit, showing how much the model is improved in comparison with the independent model estimated under the assumption that there is no correlation among the observed variables. It takes a value from 0 to 1 , and the model is judged as being a good fit if the CFI is 0.9 or greater. Moreover, the root mean square error of approximation (RMSEA) is an index that expresses the divergence between the estimated and actual distribution of the model expressed in terms of the amount of degrees of freedom. The model can be judged to have good fitness if it is 0.10 or less. The results show that GFI (0.935), AGFI (0.909), CFI (0.953), and RMSEA (0.055) satisfy all the above conditions.

\section{Discussions}

\section{Calculation of effects}

The analysis thus far has focused only on the direct effects, which are defined as effects between factors that 
Table 3. Standardizing Total Effects

\begin{tabular}{|c|c|c|c|c|c|c|}
\hline From & Locals & MNCs & $\begin{array}{c}\text { Public } \\
\text { organizations } \\
\text { \& universities }\end{array}$ & $\begin{array}{l}\text { Experiences } \\
\text { of working for } \\
\text { MNCs/JVs }\end{array}$ & $\begin{array}{l}\text { Indigenous } \\
\text { employees }\end{array}$ & $\begin{array}{l}\text { Organizational } \\
\text { learning }\end{array}$ \\
\hline $\begin{array}{l}\text { Experience of } \\
\text { working for } \\
\text { MNCs }\end{array}$ & $-0.252^{* * *}$ & $0.498^{* * *}$ & $0.141^{*}$ & 0 & 0 & 0 \\
\hline $\begin{array}{l}\text { Indigenous } \\
\text { employees }\end{array}$ & $0.253^{* * *}$ & $-0.183^{* * *}$ & -0.078 & 0 & 0 & 0 \\
\hline $\begin{array}{l}\text { Organizational } \\
\text { learning }\end{array}$ & $-0.073^{* * *}$ & $0.208^{* * *}$ & 0.054 & $0.493^{* * *}$ & $0.201^{* * *}$ & 0 \\
\hline Innovation & $-0.043^{* * *}$ & $0.122^{* * *}$ & 0.032 & $0.289^{* * *}$ & $0.118^{* * *}$ & $0.587^{* * *}$ \\
\hline
\end{tabular}

Note: ${ }^{* *},{ }^{* *}$ and $*$ indicate levels of significance of $1 \%, 5 \%$, and $10 \%$, respectively.

are directly connected, as shown in Figure 3. There also exist other indirect effects that are defined as the relationship between two factors indirectly connected via other factors. The number of indirect effects is the same as that of direct factors connected to an original factor. For example, MNCs have two indirect effects through routes via working experience with MNCs and indigenous employees. Total effects are the sum of direct and indirect effects through all routes. Accordingly, the total effects of three linkages to the final outcome of innovation are summarized in Table 3.

\section{Verification of hypotheses}

It follows from the total effects of Table 3 that the total effects of external linkages of MNCs are positively significant for innovation, while public organization and universities and locals are not significantly positive for innovation, implying that Hypothesis I is partially demonstrated. The path diagram, Figure 3 , shows that MNCs have a positive significant path to working experience, indicating that Hypothesis II is verified. Again, the path from locals to indigenous employees is significantly positive, implying that Hypothesis III is satisfied. The paths from working experience with MNCs and from indigenous employees to organizational learning are significantly positive, indicating that Hypotheses IV and V are verified. Finally, the path from organizational learning to innovation is significantly positive, demonstrating that Hypothesis IV is supported.

\section{Important factors for innovation}

The above analysis of direct and indirect effects has important implications for the innovation process of local firms in the regions. MNCs are found to have the largest impact on innovation, while locals and public organizations and universities have no significant impact. The finding regarding MNCs is consistent with the results of previous studies. Locals have a negative effect, which can be interpreted to mean that it has less effect than MNCs on organizational learning and product innovation performance. MNCs and public organizations and universities have positive direct effects on organizational learning via different channels, that is, information learned by top management from MNCs and research institutions is different from the information learned by indigenous employees from local firms. It is reasonable to consider that what top management has learned from MNCs concerns new technology or know-how, which relate directly to innovation, as the MNCs column in Table 3 indicates.

Regarding the transforming process, the learning process, including organizational learning, has the largest impact on innovation. This study focuses on $\mathrm{QC}$ and cross-functional teams in the $\mathrm{R} \& \mathrm{D}$ process. The latter is found to be more important than the former because organizational learning is significantly positive for a cross-functional team, whereas it is not significant for QC, as Table 5 indicates. Knowledge management inside the firm is thus essential. 
Let us discuss the similarities and differences in the results obtained by this study and that of Kesidoua and Szirmai (2008), which can be summarized as follows: The latter found that (i) for innovation (Innovations III and IV in our context), local knowledge spillovers are important through labor mobility and non-transaction activities inside the cluster; (ii) spinoffs from MNCs/universities do not have an effect on innovation; and (iii) knowledge flow based on local transactions does not have an effect on innovation but does so on firm performance, such as export. Accordingly, (ii) is different from our findings. The differences might originate from the motivation of the research, such as the role of the cluster or connectivity or the focus on specific or all industries. The software industry, on which Kesidoua and Szirmai (2008) focused, requires a high technological level even for local firms, but technological gaps in general between MNCs and locals in ASEAN economies, particularly in the manufacturing sectors on which this study focuses, are much larger. These differences yield the differences between the two studies.

\section{Conclusion}

As discussed above, using SEM, the innovation processes of firms in ASEAN countries are examined. In particular, the analysis identifies two channels, i.e., matching between MNCs and working experience with MNCs and between locals and indigenous employees. The total effects of the two channels on innovation are entirely opposite: the former has a positive value, whereas the latter has a negative value. Based on these results, the policy implications indicate that MNCs are important sources of innovation, and therefore, the policy of inviting MNCs to a region is effective. This is a traditional policy that developing countries have been implementing. The analysis here provides a theoretical and empirical background for this policy.

Another policy implication comes from the analysis of public organizations and universities, which were not significant for innovation but had an effect via working experience with MNCs. A policy has to target the development of a channel between public organizations and universities and locals, i.e., the construction of an open innovation system in these regions (Chesbrough, 2003, 2006). This is, however, a difficult task; the questionnaire asked whether re- spondents considered public organizations and universities as important sources of information. The figures differed between the countries, but the percentage for the reply "very important" was less than $10 \%$ on average. It seems that it will take a long time for open innovation to spread widely.

The analysis has some limitations, which are expected to be overcome in future research. In particular, the transforming process inside a firm needs further elaboration. This study examines cross-functional teams and QC as latent variables, but there must be more ways to conduct R\&D activities inside a firm. Previous studies, such as Freeman (1979), have analyzed how R\&D activities are conducted, particularly how information flows from gatekeepers to individual researchers inside a firm.

Our in-depth interviews with MNCs located in ASEAN regions show that local engineers tend to move from MNCs to local firms to seek better working conditions, although MNCs wish to retain these valuable engineers. This is a traditional pattern of technology transfers, but the number of such engineers becoming available through this channel is less than what locals require. For these regions to transform into a knowledge-based economy, this is an obstacle that needs to be solved.

\section{References}

Allen, T. J. (1977). Managing the flow technology. Cambridge, MA: MIT Press.

Allen, T. J., \& Cohen, S. I. (1969). Information flow in research and development laboratories. Administrative Science Quarterly, 14 (1), 12-19.

Bagozzi, R. P. (1980). Causal models in marketing. New York, NY: Wiley.

Balsvik, R. (2011). Is labor mobility a channel for spillovers from multinationals? Evidence from Norwegian manufacturing The Review of Economics and Statistics, 93 (1), 285-297.

Bock, R. D. (1960). Components of variance analysis as a structural and discriminal analysis for psychological tests. British Journal of Statistical Psychology, 13 (2), 151-163.

Bock, R. D., \& Bargmann, R. E. (1966). Analysis of covariance structures. Psychometrika, 31, 507-533.

Bollenn, K. A. (1989). Structural equations with latent variables. New York, NY: John Wiley \& Sons. 
Caloghirou, Y., Kastelli, I., \& Tsakanikas, A. (2004). Internal capabilities and external knowledge sources: complements or substitutes for innovative performance? Technovation, 24 (1), 29-39.

Chesbrough, H. W. (2003). Open innovation: The new imperative for creating and profiting from technology, Boston, MA: Harvard Business School Press.

Chesbrough, H. W. (2006) Open business model: How to thrive in the new innovation landscape, Boston, MA: Harvard Business School Press.

Cohen, W. M., \& Levinthal, D. A. (1990). Absorptive capacity: A new perspective on learning and innovation. Administrative Science Quarterly, 35 (1), 128-152.

Colquitt, J. A., \& Rodell, J. B. (2011). Justice, trust, trustworthiness: A longitudinal analysis integrating three theoretical perspectives. Academy of Management Journal, 54 (6), 1183-1206.

Ernst, D. (2002). Global production networks and the changing geography of innovation systems. Implications for developing countries. Economics of Innovation and New Technology, 11 (6), 497-523.

Freeman, L. C. (1979). Centrality in social networks: Conceptual clarification. Social Networks, 1 (3), 215-239.

Görg, H., \& Strobl, E. (2005). Spillovers from foreign firms through worker mobility: An empirical investigation, Scandinavian Journal of Economics, 107 (4), 693-709.

Granovetter, M. S. (1973). The strength of weak ties. American Journal of Sociology, 78 (6), 1360-1380.

Hébert, L., Very, P., \& Beamish, P. W. (2005). Expatriation as a bridge over troubled water: A knowledgebased perspective applied to cross-border acquisitions. Organization Studies, 26 (10), 1455-1476.

Kesidou, E., \& Szirmai, A. (2008). Local knowledge spillovers, innovation and export performance in developing countries: Empirical evidence from the Uruguay software cluster. The European Journal of Development Research, 20 (2), 281-298.

Lam, A. (2003). Organizational learning in multinationals: R\&D networks of Japanese and US MNEs in the UK. Journal of Management Studies, 40 (3), 673-703.

Leven, D. Z., \& Cross, R. (2004). The strength of weak ties you can trust: The mediating role of trust in effective knowledge transfer. Management Science, 50 (11), 1477-1490.
Liao, S., Fei, W. C., \& Chen, C. C. (2007). Knowledge sharing, absorptive capacity and innovation capability: An empirical study of Taiwan's knowledgeintensive industries. Journal of Information Science, 33 (3), 340-359.

Machikita, T., \& Ueki, Y. (2015). Measuring and explaining innovative capability: Evidence from southeast Asia. Asian Economic Policy Review, 10 (1), 152-173.

Mkandawire, T. (2007). Transformative social policy and innovation in developing countries. The European Journal of Development Research, 19 (1), 13-29.

Pietrobelli, C., \& Rabellotti, R. (2011). Global value chains meet innovation systems: Are there learning opportunities for developing countries? World Development, 39 (7), 1261-1269.

Poole, J. P. (2013). Knowledge transfers from multinational to domestic firms: Evidence from worker mobility. Review of Economics and Statistics, 95 (2), 393-406.

Srholec, M. (2011). A multilevel analysis of innovation in developing countries. Industrial and Corporate Change, 20 (6), 1539-1569.

Tsuji, M., Ueki, Y., \& Idota, H. (2014, November). Innovation in ASEAN economies: Internal capability, external linkages and funding sources Innovation in ASEAN Economies: Internal Capability, External Linkages and Funding Sources. Paper presented at the 14th International Convention of the East Asian Economic Association, Chulalongkorn University, Bangkok, Thailand.

Uzzi, B. (1997). Social structure and competition in interfirm networks: The paradox of embeddedness. Administrative Science Quarterly, 42 (1), 35-67.

Zahra, S. A., \& George, G. (2002). Absorptive capacity: A review, reconceptualization, and extension. Academy of Management Review, 27 (2), 185-203. 
